\title{
Vitamin D-responsive SGPP2 variants associated with lung cell expression and lung function
}

\author{
Brian J Reardon ${ }^{1 \dagger}$, Joyanna G Hansen ${ }^{1 \dagger}$, Ronald G Crystal ${ }^{2}$, Denise K Houston ${ }^{3}$, Stephen B Kritchevsky ${ }^{3}$, \\ Tamara Harris ${ }^{4}$, Kurt Lohman ${ }^{5}$, Yongmei Liu', George T O'Connor ${ }^{7,8}$, Jemma B Wilk ${ }^{8,9}$, Jason Mezey ${ }^{10,11}$, \\ Chuan Gao ${ }^{10}$ and Patricia A Cassano ${ }^{1,12^{*}}$
}

\begin{abstract}
Background: Vitamin D is associated with lung health in epidemiologic studies, but mechanisms mediating observed associations are poorly understood. This study explores mechanisms for an effect of vitamin $D$ in lung through an in vivo gene expression study, an expression quantitative trait loci (eQTL) analysis in lung tissue, and a population-based cohort study of sequence variants.

Methods: Microarray analysis investigated the association of gene expression in small airway epithelial cells with serum 25(OH)D in adult non-smokers. Sequence variants in candidate genes identified by the microarray were investigated in a lung tissue eQTL database, and also in relation to cross-sectional pulmonary function in the Health, Aging, and Body Composition (Health ABC) study, stratified by race, with replication in the Framingham Heart Study (FHS).

Results: 13 candidate genes had significant differences in expression by serum 25(OH)D (nominal $p<0.05$ ), and a genome-wide significant eQTL association was detected for SGPP2. In Health ABC, SGPP2 SNPs were associated with $\mathrm{FEV}_{1}$ in both European- and African-Americans, and the gene-level association was replicated in European-American FHS participants. SNPs in 5 additional candidate genes (DAPK1, FSTL1, KAL1, KCNS3, and RSAD2) were associated with $\mathrm{FEV}_{1}$ in Health $\mathrm{ABC}$ participants.

Conclusions: SGPP2, a sphingosine-1-phosphate phosphatase, is a novel vitamin D-responsive gene associated with lung function. The identified associations will need to be followed up in further studies.
\end{abstract}

Keywords: Vitamin D, Airflow obstruction, FEV 1 , SGPP2, FEV 1 /FVC

\section{Background}

Vitamin D is of interest in relation to a number of health outcomes, with putative function beyond its classical role in maintaining bone health. The active form of vitamin $\mathrm{D}$, 1,25-dihydroxyvitamin $\mathrm{D}\left[1,25(\mathrm{OH})_{2} \mathrm{D}\right]$, when bound to the vitamin $\mathrm{D}$ receptor (VDR), regulates the expression of genes in many molecular pathways, including inflammation, cell proliferation, cell death, and tissue-remodeling pathways [1]. Serum 25-hydroxyvitamin D [25(OH)D] is the primary circulating biomarker of vitamin $\mathrm{D}$ status, and

\footnotetext{
* Correspondence: pac6@cornell.edu

${ }^{\dagger}$ Equal contributors

'Division of Nutritional Sciences, Cornell University, 209 Savage Hall, Ithaca, NY 14853, USA

${ }^{12}$ Division of Biostatistics and Epidemiology, Department of Public Health, Weill Cornell Medical College, New York, NY, USA

Full list of author information is available at the end of the article
}

recent national survey data in the U.S. indicate $32 \%$ of Americans are at risk of vitamin $\mathrm{D}$ inadequacy or deficiency, defined as $30-49 \mathrm{nmol} / \mathrm{L}$ and $<30 \mathrm{nmol} / \mathrm{L}$ serum $25(\mathrm{OH}) \mathrm{D}$, respectively $[2,3]$.

Chronic obstructive pulmonary disease (COPD) is the third leading cause of death in the United States, and is a large and growing burden on health care [4]. While smoking is the primary risk factor for rapid lung function decline and development of COPD, about 15\% of individuals who have never smoked develop COPD and not all smokers succumb, implicating other factors, such as genetic, dietary, and lifestyle factors, in lifetime lung function patterns and disease risk [5].

Recent evidence indicates that vitamin $\mathrm{D}$, as a steroid hormone capable of influencing gene expression, may be a determinant of lung function [6]. A cross-sectional 
study in the National Health and Nutrition Examination Survey (NHANES) III reported a strong positive association between serum 25(OH)D and lung function, with clinically relevant effect sizes for forced expiratory volume in the first second $\left(\mathrm{FEV}_{1}\right)$ and forced vital capacity (FVC) [7]. However, a subsequent cross-sectional study in the U.K. reported no association between serum 25 $(\mathrm{OH}) \mathrm{D}$ and $\mathrm{FEV}_{1}$ [8]. Causal inferences are limited in the cross-sectional design, effect estimates may be biased by uncontrolled confounders such as physical activity, and, furthermore, comparisons are limited by differences in the range in serum $25(\mathrm{OH}) \mathrm{D}$ between studies. Investigations of serum $25(\mathrm{OH}) \mathrm{D}$ or high-dose vitamin $\mathrm{D}$ supplementation in relation to the risk of exacerbations in COPD patients reported overall null findings $[9,10]$. However, vitamin D supplementation led to a statistically significant reduction in COPD exacerbations in the subgroup with severe vitamin D deficiency at the study baseline (serum $25(\mathrm{OH}) \mathrm{D}<10 \mathrm{ng} / \mathrm{mL}$ ) [9], underscoring the importance of considering the potential to benefit in studies of nutritional supplementation.

In vitro animal and cell culture studies demonstrate that vitamin D-responsive genes play a role in airway remodeling and inflammation, which are key processes in the pathogenesis of COPD [11,12]. However, few studies directly investigate mechanisms for vitamin D's effect in vivo, which would strengthen the causal inference of population-level association studies. Furthermore, most experimental work to date has focused on effects of the active metabolite of vitamin D, 1,25-dihydroxyvitamin D. This metabolite is generated in the kidney for systemic circulation, and in many tissues, including lung [13]. It is not yet established whether the population-level range in serum 25-hydroxyvitamin D, the primary biomarker for vitamin D status in humans, is associated with effects similar to those seen in vitro for 1,25-hydroxyvitamin D.

We used an interdisciplinary approach to investigate the mechanisms through which vitamin D affects lung function. Genes with in vitro evidence of vitamin $\mathrm{D}$ regulation were studied to assess whether serum 25(OH)D concentration was associated with gene expression in lung epithelial tissues sampled from free-living humans. Identified genes were investigated in a study of expression quantitative trait loci (eQTL) in human lung epithelial cells to assess if genetic variation affects gene expression. Also, identified genes were investigated in an epidemiologic cohort study in relation to pulmonary function phenotypes. We hypothesized that serum $25(\mathrm{OH}) \mathrm{D}$ affects expression of vitamin D-responsive genes by modulating levels of active $1,25(\mathrm{OH})_{2} \mathrm{D}$ in lung tissue, and that variants in candidate genes directly regulated by $1,25(\mathrm{OH})_{2} \mathrm{D}$ in lung tissue are associated with $\mathrm{FEV}_{1}$ and $\mathrm{FEV}_{1} / \mathrm{FVC}$, the key parameters used for COPD diagnosis and staging.

\section{Methods}

\section{Gene expression study}

Twenty-six healthy nonsmoker adult volunteers (Additional file 1) were recruited and evaluated at the Weill Cornell Medical College General Clinical Research Center under protocols approved by the Weill Cornell Medical College Institutional Review Board, as described elsewhere [14]. Frozen sera samples were assayed for $25(\mathrm{OH}) \mathrm{D}$ by liquid chromatography-tandem mass spectrometry at the Division of Laboratory Sciences, Centers for Disease Control and Prevention (Atlanta, GA). Airway epithelial cells were collected by brushing during bronchoscopy [14], and first and second strand cDNA were synthesized from $6 \mu \mathrm{g}$ of RNA, in vitro transcribed, and fragmented according to Affymetrix protocols; samples were hybridized to the Affymetrix HG-U133 Plus 2.0 array [14]. (Additional file 2 for further details).

The microarray analysis considered 156 genes, which were identified a priori based on evidence of regulation by 1,25-dihydroxyvitamin $\mathrm{D}$ in squamous epithelial cells [1] and evidence for at least one predicted binding site for VDR (a DR3 or ER6 response element with up to 1 base mismatch from the consensus sequence) [1].

The statistical significance of fold-changes in expression between the first and third tertile of serum $25(\mathrm{OH})$ $\mathrm{D}$ was calculated using a t-test with Bayesian correction (Limma). Given that the purpose of the microarray study was to identify candidate genes to take forward to both the eQTL and the population-based cohort analysis, a statistical significance threshold of nominal $\mathrm{P}<0.05$ was used. Linear regression coefficients and the variance $\left(R^{2}\right)$ in gene expression explained by serum 25(OH)D were calculated, and included the full range of $25(\mathrm{OH}) \mathrm{D}$ concentrations.

\section{eQTL study: data collection and statistical approach}

The Expression Quantitative Trait Loci (eQTL) study was conducted using lung small airway epithelium tissue samples from 116 individuals (see Additional file 2 for details). Tissue samples were collected under protocols approved by the Weill Cornell Medical College Institutional Review Board. Associations between SNPs and gene expression of 13 vitamin D-responsive genes in lung small airway epithelium tissue were analyzed. Tissue samples were taken from a diverse cohort of 116 smokers and non-smokers of different genders and ancestries (see Table 1, Gao et al. [15]). Details of the sample collection are published elsewhere [14] and details on normalization of gene expression values are available in Gao et al. [15] SNPs were assayed using Affymetrix $500 \mathrm{k}$ arrays, which provided data on 191,959 genotypes; only SNPs with MAF of $>0.1$ were analyzed for associations with gene expression. Thus, there were far fewer SNPs available in the eQTL study in comparison to the 
Table 1 Fold change in expression and P-value of 13 genes reaching nominal $P$-value Threshold $(p<0.05)$ in expression study

\begin{tabular}{lcccc}
\hline Gene & Chromosome & Fold change* $^{*}$ & P-value & $\mathbf{R}^{\mathbf{2}}$ \\
\hline KCNS3 & 2 & -1.62 & 0.00084 & $28 \%$ \\
FSTL1 & 3 & -1.55 & 0.00163 & $40 \%$ \\
DAPK1 & 9 & -2.06 & 0.00381 & $17 \%$ \\
RSAD2 & 2 & 1.41 & 0.01103 & $16 \%$ \\
CST6 & 11 & 1.79 & 0.01516 & $20 \%$ \\
KAL1 & $X$ & -1.38 & 0.01840 & $28 \%$ \\
SLITRK6 & 13 & -1.52 & 0.02482 & $25 \%$ \\
TMEM40 & 3 & 1.55 & 0.02518 & $23 \%$ \\
EMB & 5 & 1.52 & 0.03099 & $23 \%$ \\
PTGER2 & 14 & 1.36 & 0.03574 & $9 \%$ \\
DTX4 & 11 & -1.34 & 0.03812 & $15 \%$ \\
KLF4 & 9 & 1.66 & 0.03901 & $9 \%$ \\
SGPP2 & 2 & 1.69 & 0.04491 & $24 \%$ \\
\hline
\end{tabular}

*Fold change in high versus low tertile serum 25-hydroxyvitamin D.

${ }^{\mathrm{s}} \mathrm{R}$-squared calculated in linear regression, considering the full range of serum 25 -hydroxyvitamin $D$, thus equals the proportion of variance in expression accounted for serum 25(OH)D.

Health ABC GWAS study, and although very few of the exact SNPs studied in Health ABC were in the eQTL database, the eQTL SNPs tagged the sequence variation in each gene.

SNPs within $100 \mathrm{~kb}$ of the 13 candidate genes (Additional file 3 for gene names) were tested for association with gene expression using PLINK v1.07. Quantile-quantile plots were generated in $\mathrm{R}$ and Locus Zoom [16] plots were generated to visually examine P-value distributions. The genome-wide Q-Q plot and Manhattan plot were also examined.

\section{Population-based cohort study}

The Health, Aging and Body Composition (Health $A B C$ ) cohort study enrolled a random sample of EuropeanAmericans and all African-American Medicare-eligible residents, aged 70-79 at baseline (1997) and residing in the ZIP codes in and around Memphis, TN and Pittsburgh, PA $(\mathrm{n}=3,075)$. The Institutional Review Boards at the University of Memphis, Tennessee, and the University of Pittsburgh granted approval to conduct the Health ABC Study. The Institutional Review Board at Cornell University and the Health $\mathrm{ABC}$ Publications Committee approved the use of Health $\mathrm{ABC}$ data for this study. The Framingham Heart Study (FHS) cohort $(\mathrm{n}=$ 7,694; includes individuals from the original, offspring, and third generation cohorts) [17] served as a replication cohort for cross-sectional SNP-lung function associations discovered in Health $\mathrm{ABC}$ European-Americans (Additional file 2 for further details on both cohort studies). The Institutional Review Board at the Boston University Medical Campus granted approval for the FHS.

Spirometry met American Thoracic Society criteria for acceptability $[18,19]$. Participants with missing covariate data were excluded from further consideration $(\sim 300$ in each ancestry group). Participants with an $\mathrm{FEV}_{1}$ measurement and an $\mathrm{FEV}_{1} / \mathrm{FVC}$ ratio below the Lower Limit of Normal were considered to have prevalent airflow obstruction $[19,20]$. The Illumina Human 1 M-Duo custom chip was used for genotyping in Health $A B C$ [21]. All assayed SNPs in the 13 candidate genes (identified by the expression study) with a minor allele frequency $>5 \%$ and in Hardy Weinberg equilibrium were analyzed, comprising 313 SNPs in European-Americans and 355 SNPs in African- Americans (Additional file 3).

Ordinary least squares linear regression models examined the relation between SNPs and $\mathrm{FEV}_{1}$ and $\mathrm{FEV}_{1} / \mathrm{FVC}$ in sequential regressions (using SAS 9.2). An additive genetic model was used to estimate the main effect of each SNP; SNPs with a nominal $\mathrm{P} \leq 0.02$ were further tested in dominant and recessive genetic models to refine effect estimates. In genetic studies, the risk of false positives must be minimized without ruling out true associations [22]. GWAS-scale multiple testing adjustments are not appropriate for the hypothesis-based investigation of the 13 genomic regions nominated by the gene expression study. Thus, SNPs with nominally significant $\mathrm{p}$-values are presented, and False Discovery Rate (FDR) multiple testing correction was applied [23]. Models were adjusted for age, height, cigarette smoking (smoking status and pack-years), gender, study site, and ancestry principal components.

Sensitivity analyses were performed on the top findings for the $\mathrm{FEV}_{1}$ phenotype by repeating analyses after excluding individuals with prevalent airflow obstruction or individuals with lower quality spirometry (lower reproducibility scores). Exploratory SNP $\times$ serum $25(\mathrm{OH})$ $\mathrm{D}$ interaction analyses are presented in the additional file only (Additional files 4, 5).

\section{Results}

\section{Gene expression by serum 25-hydroxyvitamin $D$}

Healthy, non-smoking adults $(\mathrm{n}=26)$ were divided into tertiles of serum 25(OH)D (range of serum 25(OH)D: 2.3$39.7 \mathrm{ng} / \mathrm{mL}$ ); the lowest tertile boundary corresponded to the cutpoint for deficiency $(<12 \mathrm{ng} / \mathrm{mL})$, and the upper tertile included only vitamin D sufficient individuals (all $\geq$ $20 \mathrm{ng} / \mathrm{mL}$ ), thus further analysis compared these two groups. Expected associations were confirmed; serum vitamin D concentrations were lower in African American participants, and slightly higher in males (Additional file 1).

Among the 156 genes studied, thirteen genes (8.3\%) had statistically significant (nominal $\mathrm{p}<0.05$ ) differences in expression between the first and third tertiles of serum 25hydroxyvitamin D (Table 1). To further characterize the 
relation of serum 25-hydroxyvitamin D with the 13 nominally significant genes, the linear association of gene expression with continuous serum 25-hydroxyvitamin D was estimated (Table 1$)$; the percent of variance $\left(R^{2}\right.$, from linear regression) explained by serum 25 -hydroxyvitamin $\mathrm{D}$ ranged from 8 to $40 \%$, and FSTL1 had the highest $\mathrm{R}^{2}$.

\section{eQTL analysis}

All 13 vitamin D-responsive genes were queried in the eQTL data, but only 12 genes had available data (no data for $R S A D 2$ ). A highly statistically significant cis eQTL reaching genome-wide significance thresholds was identified for SGPP2; a cluster of SNPs in the 3' region of SGPP2 was associated with SGPP2 gene expression in lung tissue (the lead SNP, rs13009608 had a nominal pvalue of $\left.2.99 \times 10^{-09}\right)$. Figure 1 shows gene-level results and Additional files 6 and 7 show genome-wide Q-Q and Manhattan plots, respectively. The association of rs13009608 with SGPP2 gene expression was replicated (p-value: $7.0 \times 10^{-18}$ ) in a publically available eQTL database of lymphoblastoid cell lines [24].

\section{Population-level SNP-lung function associations}

All 13 vitamin D-responsive genes identified by the microarray screen were further studied in a population-based candidate gene association study. After excluding participants with missing covariate data, 1,502 European-Americans and 996 African-Americans (81\% of full cohort) had an acceptable $\mathrm{FEV}_{1}$ and were included in the $\mathrm{FEV}_{1}$ analysis. 1,472 European-Americans and 943 African-Americans (79\% of cohort) had an acceptable $\mathrm{FEV}_{1} / \mathrm{FVC}$, and were included in the ratio analysis (Table 2).
Five SNPs in two genes (DAPK1 and SGPP2) were associated with $\mathrm{FEV}_{1}$ at a nominal $\mathrm{P}<0.02$ in EuropeanAmerican participants (P-value range: $2.88 \times 10^{-03}$ to $1.92 \times 10^{-02}$; Table 3$)$. A SNP in DAPK1 (rs11141878) had the largest effect; participants with two copies of the minor allele (recessive genotype) were $104 \mathrm{~mL}$ lower on $\mathrm{FEV}_{1}$. In African-Americans, 18 SNPs in 6 genes (DAPK1, FSTL1, KAL1, KCNS3, RSAD2, and SGPP2) were associated with $\mathrm{FEV}_{1}$ at nominal $\mathrm{P}<0.02$ (range: $1.11 \times 10^{-04}$ to $1.65 \times 10^{-02}$; Table 4). A group of 3 linked SNPs in a linked 5 ' block of SGPP2 were associated with a decreased $\mathrm{FEV}_{1}$ and a reduced $\mathrm{FEV}_{1} / \mathrm{FVC}$ ratio in African-Americans with nominal P-values $<0.02$ and FDR q-values $<0.05$ (Figure 2). A fourth SNP in SGPP2, rs4597517, was borderline significantly associated with $\mathrm{FEV}_{1}$ in African-Americans in the additive model $\left(\mathrm{p}=2.16 \times 10^{-2}\right)$, and statistically significantly associated with $\mathrm{FEV}_{1}\left(\mathrm{p}=4.28 \times 10^{-4}\right)$ in the recessive genetic model. A SNP in KCNS3 (rs3747515) had the largest effect on $\mathrm{FEV}_{1}$ in African-Americans; participants with the recessive genotype were $244 \mathrm{~mL}$ higher on $\mathrm{FEV}_{1}$. Due to linkage, some SNP associations were redundant; thus, SNPs in the same gene with an $R^{2} \geq 0.9$ (indicating strong linkage) are assumed to represent the same effect and redundant SNPs are presented in the online additional materials only (Additional files 8, 9).

In European-Americans, $1 \mathrm{SNP}$ in KLF4 was associated with the $\mathrm{FEV}_{1} / \mathrm{FVC}$ ratio (P-value $1.15 \times 10^{-2}$; Additional file 9). In African-Americans, 14 SNPs in 3 genes (FSTL1, KAL1, and SGPP2) were associated with the ratio at a nominal $\mathrm{P}<$ 0.02 (range: $1.32 \times 10^{-03}$ to $1.27 \times 10^{-02}$; Additional file 9).

A sensitivity analysis explored whether the SNP-FEV 1 associations primarily reflected effects of genetic variation on risk of COPD; analyses were repeated after excluding

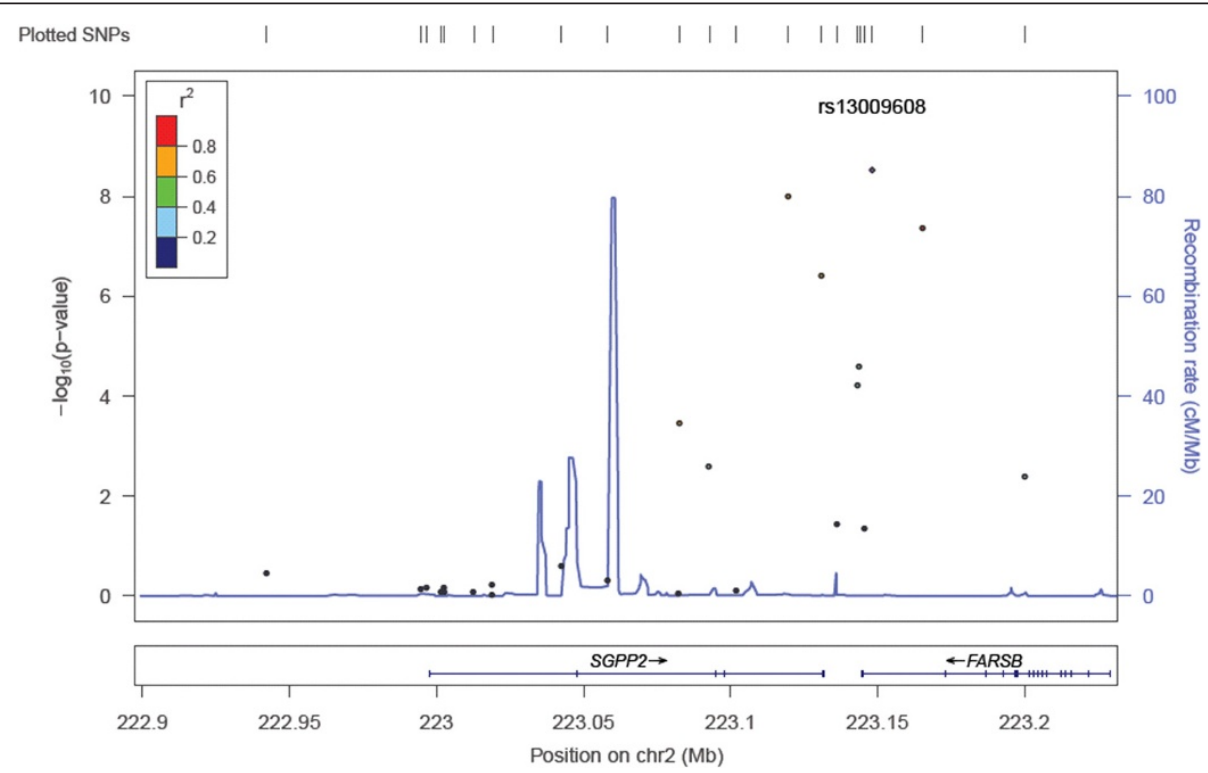

Figure 1 Locus Zoom plot of SGPP2 eQTL associations. 
Table 2 Characteristics of Health, Aging and Body Composition study participants included in the $\mathrm{FEV}_{1}$ phenotype* analysis, stratified by race

\begin{tabular}{lcc}
\hline Covariate & $\begin{array}{c}\text { African-Americans } \\
(\mathbf{N}=\mathbf{9 9 6})\end{array}$ & $\begin{array}{c}\text { European-Americans } \\
\mathbf{( N = 1 , 5 0 2 )}\end{array}$ \\
\hline Age, years** & $73.4(2.9)$ & $73.7(2.8)$ \\
Women (\%) & $553(55.5)$ & $708(47.1)$ \\
Memphis, TN site (\%) & $464(46.6)$ & $759(50.5)$ \\
Former Smokers (\%) & $398(40)$ & $746(49.7)$ \\
Current Smokers (\%) & $167(16.8)$ & $99(6.6)$ \\
Pack-years & $29.5(24.1)$ & $36.5(31.9)$ \\
FEV, mL & $1948.7(569.4)$ & $2305.4(654.3)$ \\
FEV 1 /FVC & $75.5(9.3)$ & $74.4(7.9)$ \\
Height, cm & $165.7(9.4)$ & $167(9.3)$ \\
Mean 25(OH)D (ng/mL) ${ }^{* * *}$ & $20.9(10.6)$ & $29(11)$ \\
COPD, defined by LLN (\%) & $66(7.0)$ & $110(7.5)$
\end{tabular}

*All participants in table have $\mathrm{FEV}_{1}$ data; approximately 50 fewer individuals have $\mathrm{FEV}_{1} / \mathrm{FVC}$ ratio data, but participant characteristics are the same for both phenotypes.

**Data shown are mean (SD) or number (\%).

***Serum 25(OH)D measured for 1,412 (94\%) European-Americans and 864 (87\%) African-Americans with the $\mathrm{FEV}_{1}$ phenotype, and for 1,383 EuropeanAmericans and 864 African-Americans with the $\mathrm{FEV}_{1} / \mathrm{FVC}$ phenotype.

110 European Americans and 64 African-Americans with prevalent airflow obstruction (as an indicator of COPD). For European-Americans there was little or no difference in analyses with and without prevalent cases. A BlandAltman analysis showed that for SNPs in SGPP2, the effect estimates for African-Americans were attenuated after excluding cases of prevalent airflow obstruction (data not shown). Thus, the SGPP2 SNPs that had statistically significant associations with $\mathrm{FEV}_{1}$ were further tested in logistic regression models to assess the SGPP2-outcome association in African-Americans. Individuals with two copies of the SNP most statistically significantly associated with $\mathrm{FEV}_{1}$, rs4528748, had a 2.6-fold increased risk of airflow obstruction. All 3 SGPP2 SNPs had odds ratios above 2 for the SNP-COPD association, and all confidence intervals excluded 1 (Table 5), supporting a role for SGPP2 in mediating COPD risk.
There was consistency of findings across both phenotypes and both ancestry groups for 2 genes, namely SGPP2 and DAPK1. SNPs in SGPP2 and DAPK1 were associated with $\mathrm{FEV}_{1}$ in both European-Americans and African-Americans, and SNPs in SGPP2 were also associated with $\mathrm{FEV}_{1} / \mathrm{FVC}$ and with risk of prevalent airflow obstruction in African-Americans.

Genes containing SNPs significantly associated with $\mathrm{FEV}_{1}$ or $\mathrm{FEV}_{1} / \mathrm{FVC}$ in Health $\mathrm{ABC}$ European-Americans, namely $D A P K 1, K L F 4$, and SGPP2, were further evaluated in the FHS cohort. Gene-level replication was observed for DAPK1 and SGPP2; 23 out of 340 SNPs in DAPK1 (6.8\%) and 23 out of 145 SNPs (15.8\%) in SGPP2 were associated with cross-sectional $\mathrm{FEV}_{1}$ at a nominal P-value $<0.05$ in the FHS cohort, although these comprised different SNPs than the ones associated with lung function in Health $\mathrm{ABC}$ (Additional file 10).

\section{Discussion}

Using an interdisciplinary genomics approach we investigated vitamin D and lung outcomes. SGPP2, a phosphatase involved in the sphingosine-1-phosphate signaling pathway, was identified in all stages of the study as a promising candidate gene contributing to vitamin D-mediated associations with lung function. SGPP2 is differentially expressed in vivo in lung epithelial cells by serum $25(\mathrm{OH}) \mathrm{D}$. eQTL analysis demonstrates that sequence variants in SGPP2 are associated with lung cell gene expression. Although the eQTL finding does not prove that vitamin D regulation affects gene expression, the location of associated variants in regulatory regions supports the hypothesis of vitamin D regulation. Furthermore, a group of 3 linked SNPs in the SGPP2 promoter region are associated with lower $\mathrm{FEV}_{1}$, a reduced $\mathrm{FEV}_{1} / \mathrm{FVC}$ ratio, and a 2-3 fold increased risk of airflow obstruction in African-Americans, suggesting that a causal variant in this region may affect SGPP2 function and/or vitamin $\mathrm{D}$ binding, and, consequently, lung outcomes. Additionally, a SNP in SGPP2 is associated with $\mathrm{FEV}_{1}$ in Health ABC European-Americans and SGPP2 variants were also associated with $\mathrm{FEV}_{1}$ in the Framingham Heart Study, confirming effects across racial groups and in two cohort

Table 3 The association of SNPs in vitamin D-responsive genes (nominal $P<2.0 \times 10^{-02}$ ) with FEV $(\mathrm{mL}$ ) for EuropeanAmericans in the Health, Aging and Body Composition study (sorted by gene)*

\begin{tabular}{lcccccccc}
\hline Gene & RS\# & Chr & Coded allele & MAF (\%) & $\boldsymbol{\beta}^{* *}$ & SE & Nominal P & Model \\
\hline DAPK1 & rs11141878 & 9 & A & 36 & -103.98 & 36.3 & $4.26 \times 10^{-03}$ & R \\
& rs4877361t & 9 & G & 14 & 72.47 & 27.4 & $8.17 \times 10^{-03}$ & D \\
& rs4878089 & 9 & A & 46 & 39.68 & 16.9 & $1.92 \times 10^{-02}$ \\
SGPP2 & rs4674656 & 2 & A & 25 & -58.70 & 19.7 & $2.88 \times 10^{-03}$ & A \\
\hline
\end{tabular}

tone redundant SNP not shown.

*Abbreviations: Chr, chromosome; MAF, minor allele frequency; $\beta$, regression coefficient; $S E$, standard error; $A=$ additive genetic model, $D=$ dominant model, $\mathrm{R}=$ recessive model.

**Beta-coefficient estimates the association of allele with $\mathrm{FEV}_{1}$, based on genetic model shown and adjusted for age, height, smoking, gender, study site, and ancestry principal components. 
Table 4 The association of SNPs in vitamin D-responsive genes (nominal $P<2.0 \times 10^{-02}$ ) with FEV $(\mathrm{mL})$ for AfricanAmericans in the Health, Aging and Body Composition study (sorted by gene)*

\begin{tabular}{|c|c|c|c|c|c|c|c|c|}
\hline Gene & RS\# & Chr & Coded allele & MAF (\%) & $\beta^{* *}$ & SE & Nominal P & Model \\
\hline$\overline{D A P K 1}$ & rs3128491 & 9 & $G$ & 33 & 51.48 & 21.4 & $1.65 \times 10^{-02}$ & $A$ \\
\hline \multirow[t]{3}{*}{ FSTL1 } & rs4676781 & 3 & $\mathrm{~T}$ & 8 & -110.13 & 35.3 & $1.88 \times 10^{-03}$ & A \\
\hline & rs13100865 & 3 & G & 9 & -105.96 & 35.0 & $2.54 \times 10^{-03}$ & A \\
\hline & rs13097755t & 3 & T & 28 & -60.46 & 21.6 & $5.20 \times 10^{-03}$ & A \\
\hline \multirow[t]{2}{*}{$K A L 1$} & rs6530200 & 23 & $\mathrm{~T}$ & 47 & -45.28 & 16.8 & $7.20 \times 10^{-03}$ & A \\
\hline & rs974655 & 23 & A & 49 & 79.23 & 30.3 & $9.14 \times 10^{-03}$ & D \\
\hline KCNS3 & rs1031771† & 2 & A & 16 & 243.76 & 83.5 & $3.60 \times 10^{-03}$ & $\mathrm{R}$ \\
\hline \multirow[t]{4}{*}{ RSAD2 } & rs4669114tt & 2 & G & 10 & -119.55 & 36.2 & $9.93 \times 10^{-04}$ & D \\
\hline & rs6431837 & 2 & C & 47 & -101.06 & 33.6 & $2.66 \times 10^{-03}$ & R \\
\hline & rs7570384 & 2 & C & 38 & -55.35 & 20.1 & $5.88 \times 10^{-03}$ & A \\
\hline & rs4669111 & 2 & A & 41 & -49.75 & 20.1 & $1.34 \times 10^{-02}$ & A \\
\hline SGPP2 & rs4528748t十 & 2 & C & 27 & -209.95 & 54.1 & $1.11 \times 10^{-04 * * *}$ & $\mathrm{R}$ \\
\hline
\end{tabular}

*Abbreviations: Chr, chromosome; MAF, minor allele frequency; $\beta$, regression coefficient; $S E$, standard error; $A=$ additive genetic model, $D=$ dominant model, $\mathrm{R}=$ recessive model.

**Beta-coefficient estimates the association of allele with $\mathrm{FEV}_{1}$, based on genetic model shown, adjusted for age, height, smoking, gender, study site, and ancestry principal components.

***FDR q-value $<0.05$.

tone redundant SNP not shown.

††two redundant SNPs not shown.

studies. This multi-faceted approach identifies putative mechanistic pathways for observed vitamin D-lung function associations while reducing the chance of false positive results.

SGPP2 plays a key role in the sphingolipid signaling pathway through dephosphorylation of sphingosine-1-phosphate (S1P) to sphingosine, which is then converted to ceramide or back to sphingosine-1-phosphate by other enzymes [25]. Sphingosine-1-phosphate acts as both an intracellular and extracellular signaling molecule, and regulates critical cell processes including apoptosis, cell growth, and immune function $[25,26]$. Altered sphingolipid concentrations have important ramifications for lung function; ceramide concentrations are elevated in COPD, contributing to lung alveolar destruction [25]. Little research exists on SGPP2, although a 2006 paper showed that SGPP2 is up-regulated in response to inflammatory stimuli in endothelial cells, suggesting a possible role in mediating inflammation in lung tissue [27]. However, SGPP2's biological function to alter sphingosine-1phosphate concentrations suggests that this gene contributes to the regulation of sphingolipid signaling pathways in lung tissue.

We identified several additional genes, namely DAPK1, KCNS3, and FSTL1, and all three had mechanistic links to lung function identified through gene ontology analysis and literature reviews (Additional files 11 and 12). Expression of all three genes was strongly associated with serum $25(\mathrm{OH}) \mathrm{D}$, and variants in these genes were associated with pulmonary function in the Health $\mathrm{ABC}$ cohort study. However, variants were not replicated in the Framingham Heart Study, nor were there observed eQTL associations. DAPK1, which is down-regulated by $1,25(\mathrm{OH})_{2} \mathrm{D}$ both in vivo and in vitro, is a pro-apoptotic kinase linked to cytoskeletal remodeling and regulation of inflammatory gene expression in macrophages [28,29]. SNPs in KCNS3, which encodes a voltage-gated potassium channel protein, were associated with airway hyperresponsiveness in past studies [30], which is of interest given postulated associations of airways hyperresponsiveness with an accelerated rate of $\mathrm{FEV}_{1}$ decline and risk of COPD [31]. FSTL1 up-regulates pro-inflammatory cytokines; in mice, the highest expression level is in lung [32]. Dexamethasone, which is a glucocorticoid used to treat both asthma and COPD, is associated with expression of both KCNS3 and FSTL1; interestingly, there are striking similarities in the effects of dexamethasone and 1,25-dihydroxyvitamin on the expression of these genes. The combination of 1,25-dihydroxyvitamin $\mathrm{D}$ with dexamethasone was investigated in vitro as an anti-inflammatory treatment; our results suggest the strong possibility of synergistic effects for this treatment combination (Additional file 12 for references).

A major strength of this study is that it translates in vitro animal and cell culture studies to an in vivo study, and then extends to study population-level SNP associations with lung phenotypes, which are partially replicated in an independent cohort. The multi-stage approach identified SGPP2 as a promising vitamin D-responsive gene for further study. The demonstration of differential gene expression in lung tissue associated with the physiologic range of 25-hydroxyvitamin $\mathrm{D}$ in a diverse sample of free-living humans confirms in vitro studies, and, while our study does not manipulate vitamin $\mathrm{D}$, the in vivo evidence of association is novel. The Health $\mathrm{ABC}$ population-based 


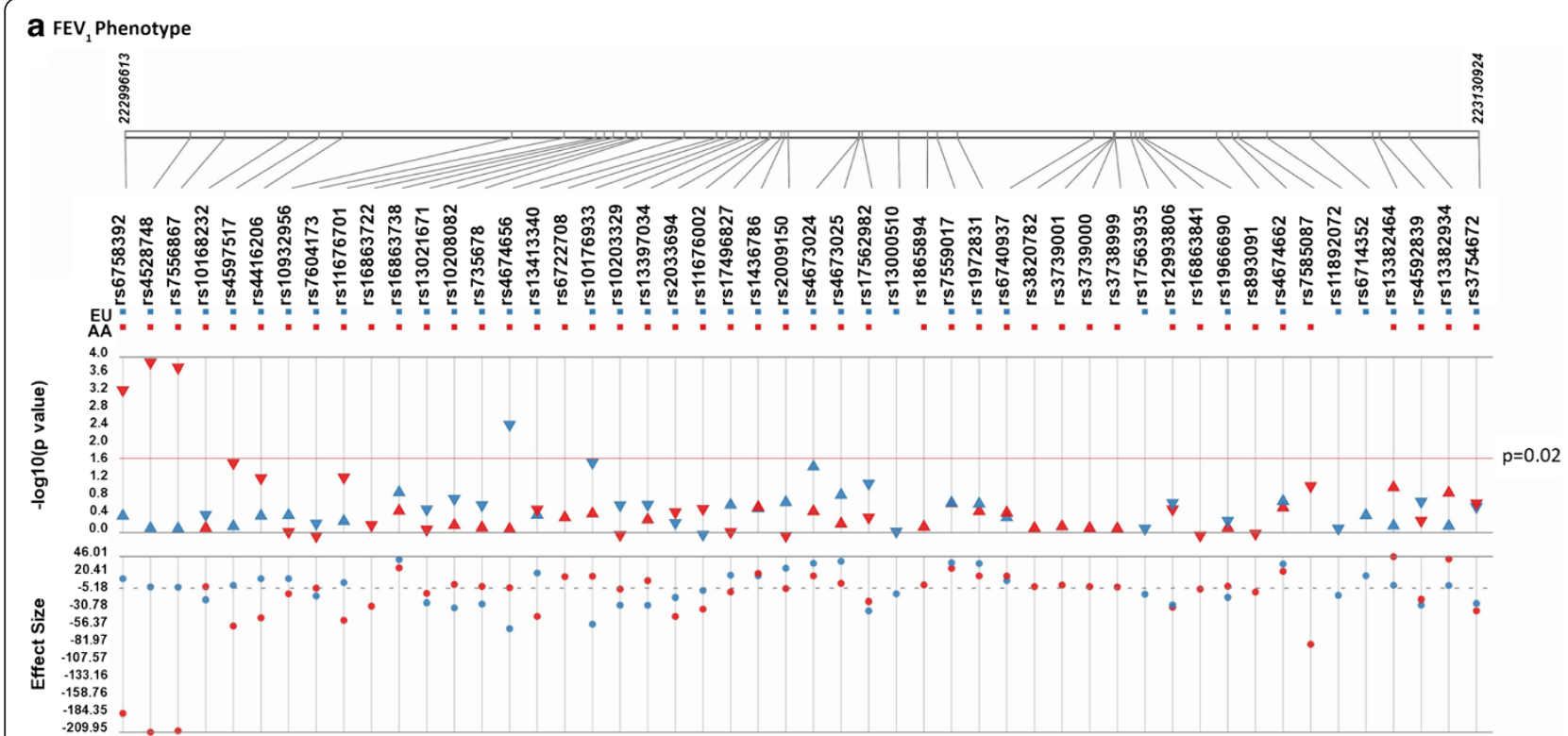

\section{b FEV $/$ FVC Phenotype}

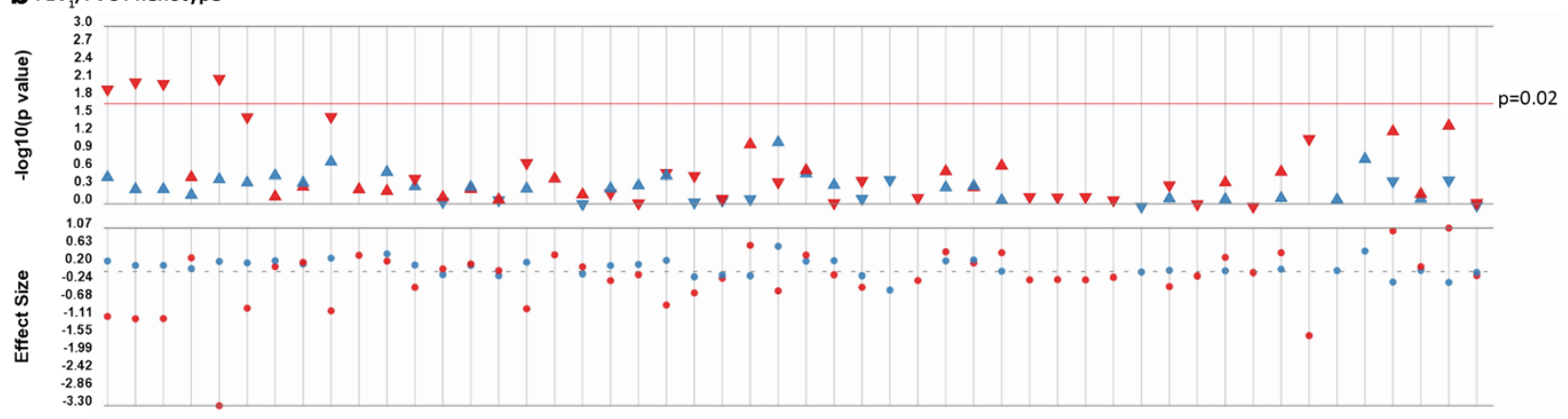

C Linkage Disequilibrium of SGPP2

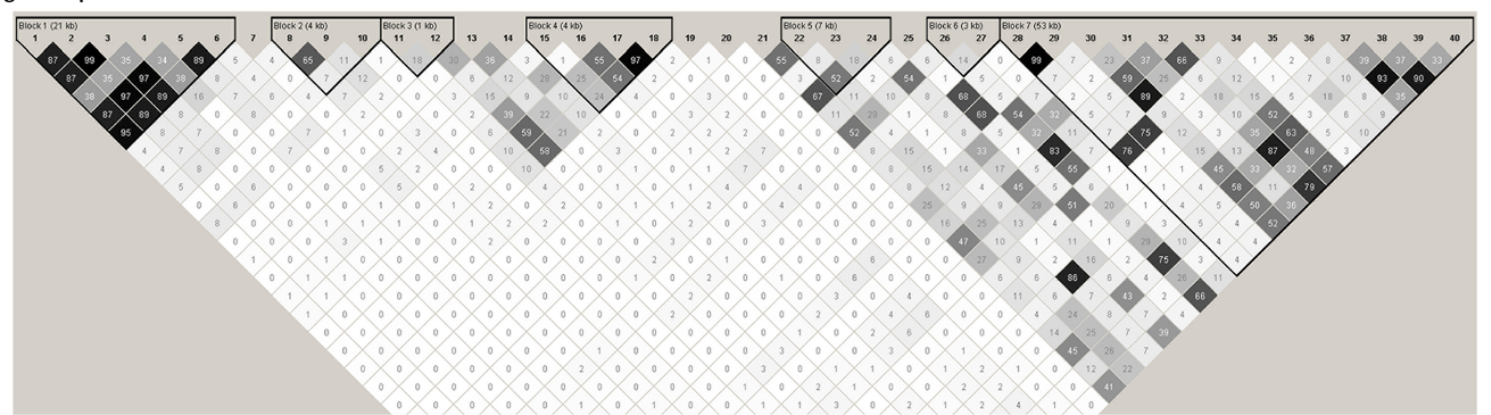

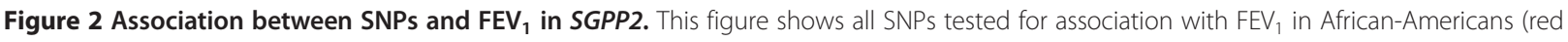
markers) and European-Americans (blue markers) in Health ABC. The top graph shows the p-values for each SNP on a negative log scale. The threshold for significance, nominal $P=2 \times 10^{-02}$, is shown as a line in the figure. Effect estimates $\left(\beta_{S N P}\right)$ for $F E V_{1}$ (in $\mathrm{mL}$ ) for each ancestry group are shown underneath the P-values (dotted line shows null value of 0 ). Effect estimates and p-values are from recessive, dominant, or additive genetic models for SNPs with $p<0.02$, and from an additive genetic model for all other SNPs. Finally, the linkage disequilibrium structure of SGPP2 in the Health ABC European-American population is shown at the bottom, with darker shading representing higher $R^{2}$.

cohort study included high-quality spirometry, detailed information on confounding factors such as smoking and population stratification, and comprised $40 \%$ AfricanAmerican participants, thus allowing consideration of this understudied population in genomic research. $\mathrm{FEV}_{1}$ is a predictor of all-cause mortality [33], and thus SNP $-\mathrm{FEV}_{1}$ associations are clinically relevant. Although associations between SNPs and the $\mathrm{FEV}_{1} / \mathrm{FVC}$ ratio were also investigated, the associations were not as strong as for $\mathrm{FEV}_{1}$. Thus, vitamin D may have a stronger association with 
Table 5 Associations of SNPs in SGPP2 with risk of prevalent COPD* in African-Americans in the Health, Aging and Body Composition Study

\begin{tabular}{lcccc}
\hline SNP** & & \multicolumn{2}{c}{$\mathbf{9 5 \%}$ Confidence interval } & \\
\cline { 3 - 4 } & Odds ratio & Lower & Upper & Nominal P-value \\
\hline rs4528748 & 2.63 & 1.19 & 5.80 & $1.64 \times 10^{-02}$ \\
rs7556867 & 2.71 & 1.23 & 5.99 & $1.35 \times 10^{-02}$ \\
rs6758392 & 2.34 & 1.07 & 5.11 & $3.33 \times 10^{-02}$
\end{tabular}

${ }^{*}{ }^{*} \mathrm{OPD}$ defined as $\mathrm{FEV}_{1}$ and $\mathrm{FEV}_{1} / \mathrm{FVC}$ ratio below the Lower Limit of Normal. *All SNPs modeled as recessive (two copies of the minor allele) to reflect the most significant coding from Table 3, and models adjusted for age, height, smoking, gender, study site, and ancestry principal components.

overall lung health versus the risk of COPD. This study identifies plausible biological mechanisms that support a true effect of vitamin D on lung function, and will help to guide the design and analysis of randomized controlled intervention trials of the role of vitamin D in lung disease.

Given that the microarray analysis was used exclusively as a candidate screen, limitations including the lack of qPCR confirmation (not possible due to sample volume limitations), use of nominal $\mathrm{P}$ values, and the lack of racestratified analysis (not possible due to sample size limitations) are less of a concern. As expected, the proportion of participants in the race/ethnicity groups varied by tertile of serum $25(\mathrm{OH}) \mathrm{D}$ given the role of skin pigmentation in vitamin $\mathrm{D}$ synthesis in response to sunlight [2]. Race may either confound the serum $25(\mathrm{OH}) \mathrm{D}$ - gene expression association, or, race may be a causal antecedent variable that, in part, causes serum $25(\mathrm{OH}) \mathrm{D}$ concentration and, in turn, differences in gene expression; adjusting for race may be an over-adjustment. Of note, in regressions adjusted for race the regression coefficients for the serum $25(\mathrm{OH}) \mathrm{D}$-gene expression association were similar to unadjusted analyses.

While the studies were all cross-sectional, which limits causal inference, the harmony of findings across different designs partly mitigates this concern. Although it would have been ideal to use the same samples in all studies (that is, expression, eQTL and SNP-lung function studies), practical limitations led to the use of different samples in each phase. Finally, although gene-level replication was observed for SGPP2 and DAPK1, the specific SNPs associated with $\mathrm{FEV}_{1}$ in Health $\mathrm{ABC}$ did not reach statistical significance in FHS. We hypothesize that the SGPP2 SNPs identified in the two cohort studies may be tagging the same unknown causal variant(s) or there may be multiple SGPP2 regulatory regions associated with lung function. Additionally, the strongest SNP-lung function associations in Health $\mathrm{ABC}$ were in African-Americans, and, because FHS includes only European Americans, the replication was partial. In summary, SNPs in SGPP2 were statistically significantly associated with lung outcomes after FDR multiple testing adjustment and a highly statistically significant lung eQTL was identified for SGPP2; SGPP2 emerged as a clear candidate in all stages of this work.

\section{Conclusions}

This study establishes for the first time that physiological concentrations of serum $25(\mathrm{OH}) \mathrm{D}$ are associated with differences in gene expression in human lung tissue, and that candidate vitamin $\mathrm{D}$ responsive genes are associated with pulmonary function outcomes. We hypothesize that genetic variants associated with pulmonary function in our study affect binding of the VDR/RXR heterodimer to the genome; however, further studies are needed to map lung tissuespecific regulatory regions. Recent evidence shows that vitamin D regulatory elements (VDREs) are located both proximal and distal to vitamin D-responsive genes at promoter regions and enhancer regions, respectively, and that VDR/ RXR binding is cell-type specific [34]. This emphasizes the importance of genome-wide VDR/RXR mapping in lung cells to identify regulatory regions [34]. Additionally, in vitro studies of bronchial epithelial cells to directly assess gene expression changes due to vitamin $\mathrm{D}$ would contribute to the current understanding. Overall, the results of our study identify putative mechanisms through which vitamin D may affect lung function and, suggest a physiological range for 25-hydroxyvitamin $\mathrm{D}$ at which differential responses occur at the molecular level. Demonstrated associations strengthen the evidence for monitoring serum $25(\mathrm{OH}) \mathrm{D}$ concentrations in individuals at risk of rapid decline in lung function.

\section{Additional files}

Additional file 1: Table S1. Characteristics of 26 Non-smoking Human Volunteers in the Gene Expression Study, by Tertile of Serum 25-Hydroxyvitamin D Concentration.

Additional file 2: Methods and Results.

Additional file 3: Table S2. The distribution of studied SNPs in Thirteen Vitamin D-responsive Genes for European- and African-American Ancestry Groups in the Health ABC Cohort Study.

Additional file 4: Table S3. SNP by $25(\mathrm{OH}) \mathrm{D}$ interactions associated with the $\mathrm{FEV}_{1}$ phenotype in a) European-Americans, and b) African-Americans.

Additional file 5: Table S4. SNP by serum 25(OH)D interactions in association with the $\mathrm{FEV}_{1} / \mathrm{FVC}$ phenotype in a) European-Americans, and b) African-Americans.

Additional file 6: Figure S1. Genome-wide Quantile-Quantile Plot for SGPP2 eQTL findings.

Additional file 7: Figure S2. Genome-wide Manhattan Plot for SGPP2 eQTL findings.

Additional file 8: Table S5. The most statistically significant associations (nominal $\mathrm{P}<2.0 \times 10^{-02}$ ) between single nucleotide polymorphisms in vitamin Dresponsive genes and $\mathrm{FEV}_{1}$ for a) European-Americans and b) African-Americans (all SNPS, including redundant SNPs are shown).

Additional file 9: Table S6. The most statistically significant associations (nominal $\mathrm{P}<2.0 \times 10^{-02}$ ) between single nucleotide polymorphisms in vitamin D-responsive genes and the FEV 1 /FVC ratio for a) European-Americans and b) African-Americans in the Health $A B C$ cohort. 
Additional file 10: Table S7. Gene-level replication of Health $A B C$ European-American SNP associations with $\mathrm{FEV}_{1}$ using the Framingham Heart Study cohort.

Additional file 11: Table S8. Gene Ontology of Thirteen Nominally Significant Candidate Genes from the UniProtKb-GOA Database (http://www. ebi.ac.uk/QuickGO/.

Additional file 12: Table S9. Evidence Supporting the Role in Lung Health and/or Regulation by Glucocorticoids For Genes Differentially Expressed by Serum Vitamin D.

\section{Abbreviations}

COPD: Chronic obstructive pulmonary disease; $\mathrm{FEV}_{1}$ : Forced expiratory volume in the first second; FDR: False discovery rate; FVC: Forced vital capacity; 25(OH)D: 25-hydroxyvitamin D; 1,25(OH) 2 D: 1,25-dihydroxyvitamin D; NHANES: National Health and Nutrition Examination Survey; CST6: cystatin E/M; DAPK1: Death associated protein kinase 1; DTX4: Deltex homolog 4; EMB: Embigin; FSTL1: Follistatin-like 1; KAL1: Kallmann syndrome 1 sequence; KCNS3: Potassium voltage-gated channel, delayed-rectifier, subfamily S, member 3; KLF4: Kruppel-like factor 4; PTGER2: Prostaglandin E receptor 2(subtype EP2); RSAD2: Radical S-adenosyl methionine domain containing 2; SLITRK6: SLIT and NTRK-like family, member 6; SGPP2: Sphingosine-1phosphate phosphatase 2; TMEM40: Transmembrane protein 40

\section{Competing interests}

The authors declare that they have no competing interests.

\section{Authors' contributions}

All authors satisfy the requirements for authorship and contributorship. BR, RC and PAC designed and conducted the expression study; YL, KL, SK and TH conducted the Health ABC GWAS study, which provided data for this paper; JGH, BR and PAC designed the Health ABC SNP study and JGH and PAC conducted the SNP study; JGH, PAC, JW and GO'C conducted the replication analysis in FHS, and JGH, PAC, $J M$ and CG conducted the eQTL analysis and interpretation. All coauthors read and edited the final manuscript.

\section{Acknowledgements}

The authors thank Alex Gileta, who contributed to the eQTL analysis during the time he was an undergraduate senior at Cornell University, and a member of the Cassano Research Group. In addition, the authors thank Yae Strulovici-Barel from Weill Cornell Medical College for uploading the gene expression files to the GEO data repository. Finally, the authors thank the participants of the Health $A B C$ study, for giving of their time, and the Health ABC study team, including the coordinating center at UCSF and at the NIA, for all of the infrastructure and support throughout this project.

\section{Funding}

This research was supported by National Institutes of Health, National Heart Lung and Blood Institute R03 HL095414 (PAC) and P50 HL084936 (RGC), by RC1-AG035835 (SK, PI; PAC, PI subcontract), and by NRSA Institutional Research Training Grant T32-DK-7158-36 (JGH). This research also was supported by R01AG029364, by NIA contracts N01AG62101, N01AG62103, and N01AG62106, and by the Ashken Foundation (RGC). The genome-wide association study was funded by NIA grant R01-AG032098-01A1 to Wake Forest University Health Sciences and genotyping services were provided by the Center for Inherited Disease Research (CIDR). CIDR is fully funded through a federal contract from the National Institutes of Health to The Johns Hopkins University, contract number HHSN268200782096C. This research was supported in part by the Intramural Research Program of the NIH, National Institute on Aging. Research was conducted in part using data and resources from the Framingham Heart Study of the NHLBl of the NIH and Boston University School of Medicine. The analyses reflect intellectual input and resource development from the Framingham investigators participating in the SNP Health Association Resource (SHARe) project. This work was partially supported by the NHLBl's Framingham Heart Study (Contract No. N01-HC-25195) and its contract with Affymetrix, Inc. for genotyping services (Contract No. N02-HL-6-4278). A portion of this research utilized the Linux Cluster for Genetic Analysis (LinGA-II) funded by the Robert Dawson Evans Endowment of the Department of Medicine at Boston University School of Medicine and Boston Medical Center.

\section{Author details}

'Division of Nutritional Sciences, Cornell University, 209 Savage Hall, Ithaca, NY 14853, USA. ²Department of Genetic Medicine, Weill Cornell Medical College, New York, NY, USA. ${ }^{3}$ Sticht Center on Aging, Wake Forest School of Medicine, Winston-Salem, NC 27157, USA. ${ }^{4}$ Intramural Research Program, National Institute on Aging, Laboratory of Epidemiology, Demography, and Biometry, Gateway Building, 3C309, 7201 Wisconsin Avenue, Bethesda, MD 20892, USA. ${ }^{5}$ Division of Public Health Sciences, Department of Biostatistical Sciences, Wake Forest School of Medicine, Winston-Salem, NC 27157, USA. ${ }^{6}$ Division of Public Health Sciences, Department of Epidemiology \& Prevention, Wake Forest School of Medicine, Winston-Salem, NC 27157, USA. ${ }^{7}$ Section of Pulmonary, Allergy \& Critical Care Medicine, Department of Medicine, Boston University School of Medicine, Boston, MA, USA. ${ }^{8}$ The National Heart, Lung, and Blood Institute's Framingham Heart Study, Framingham, MA, USA. ${ }^{9}$ Division of Aging, Department of Medicine, Brigham and Women's Hospital and Harvard Medical School, Boston, MA, USA. ${ }^{10}$ Biological Statistics and Computational Biology, Cornell University, Ithaca, NY 14853, USA. ${ }^{11}$ Department of Medical Genetics, Weill Cornell Medical College, New York, NY, USA. ${ }^{2}$ Division of Biostatistics and Epidemiology, Department of Public Health, Weill Cornell Medical College, New York, NY, USA.

Received: 21 January 2013 Accepted: 8 November 2013

Published: 25 November 2013

\section{References}

1. Wang $T$, Tavera-Mendoza LE, Laperriere $D$, Libby E, MacLeod NB, Nagai $Y$, Bourdeau V, Konstorum A, Lallemant B, Zhang R, et al: Large-scale in silico and microarray-based identification of direct 1,25-dihydroxyvitamin D3 target genes. Mol Endocrinol 2005, 19(11):2685-2695.

2. Ross AC, Institute of Medicine (U. S.). Committee to Review Dietary Reference Intakes for Vitamin D and Calcium: Dietary reference intakes for calcium and vitamin D. Washington, DC: National Academies Press; 2011.

3. Looker AC, Lacher DA, et al: Vitamin D status: United States, 2001-2006. NCHS Data Brief 2011, 59:1-7.

4. Minino AM: Death in the United States, 2009. NCHS Data Brief 2011(64):1-8.

5. Eisner MD, Anthonisen N, Coultas D, Kuenzli N, Perez-Padilla R, Postma D, Romieu I, Silverman EK, Balmes JR: An official American Thoracic Society public policy statement: Novel risk factors and the global burden of chronic obstructive pulmonary disease. Am J Respir Crit Care Med 2010, 182(5):693-718.

6. Finklea JD, Grossmann RE, Tangpricha V: Vitamin D and chronic lung disease: a review of molecular mechanisms and clinical studies. Adv Nutr 2011, 2:244-253.

7. Black PN, Scragg R: Relationship between serum 25-hydroxyvitamin D and pulmonary function in the third national health and nutrition examination survey. Chest 2005, 128(6):3792-3798.

8. Shaheen SO, Jameson KA, Robinson SM, Boucher BJ, Syddall HE, Aihie Sayer A, Cooper C, Holloway JW, Dennison EM: Relationship of vitamin D status to adult lung function and COPD. Thorax 2011, 66(8):692-698.

9. Lehouck A, Mathieu C, Carremans C, Baeke F, Verhaegen J, Van Eldere J, Decallonne B, Bouillon R, Decramer M, Janssens W: High doses of vitamin $D$ to reduce exacerbations in chronic obstructive pulmonary disease: a randomized trial. Ann Int Med 2012, 156(2):105-114.

10. Kunisaki KM, Niewoehner DE, Connett JE: Vitamin D levels and risk of acute exacerbations of chronic obstructive pulmonary disease: $\mathrm{A}$ prospective cohort study. Am J Respir Crit Care Med 2012, 185(3):286-290.

11. Wittke A, Chang A, Froicu M, Harandi OF, Weaver V, August A, Paulson RF, Cantorna MT: Vitamin D receptor expression by the lung microenvironment is required for maximal induction of lung inflammation. Arch Biochem Biophys 2007, 460(2):306-313.

12. Bosse Y, Maghni K, Hudson TJ: 1alpha,25-dihydroxy-vitamin D3 stimulation of bronchial smooth muscle cells induces autocrine, contractility, and remodeling processes. Physiol Genomics 2007, 29(2):161-168.

13. Hansdottir S, Monick MM, Hinde SL, Lovan N, Look DC, Hunninghake GW: Respiratory epithelial cells convert inactive vitamin $D$ to its active form: potential effects on host defense. J Immunol 2008, 181(10):7090-7099.

14. Harvey BG, Heguy A, Leopold PL, Carolan BJ, Ferris B, Crystal RG: Modification of gene expression of the small airway epithelium in response to cigarette smoking. J Mol Med (Berl) 2007, 85(1):39-53. 
15. Gao C, Tignor N, Salit J, Strulovici-Barel Y, Hackett N, Crystal RG, Mezey JG: HEFT: eQTL analysis of many thousands of expressed genes while simultaneously controlling for hidden factors. Bioinformatics 2013: . in press.

16. Pruim RJ, Welch RP, Sanna S, Teslovich TM, Chines PS, Gliedt TP, Boehnke M, Abecasis GR, Willer CJ: LocusZoom: regional visualization of genome-wide association scan results. Bioinformatics 2010, 26(18):2336-2337.

17. Hancock DB, Eijgelsheim M, Wilk JB, Gharib SA, Loehr LR, Marciante KD, Franceschini N, van Durme YM, Chen TH, Barr RG, et al: Meta-analyses of genome-wide association studies identify multiple loci associated with pulmonary function. Nat Genet 2010, 42(1):45-52.

18. Miller MR, Hankinson J, Brusasco V, Burgos F, Casaburi R, Coates A, Crapo R, Enright $P$, van der Grinten $C P$, Gustafsson $P$, et al: Standardisation of spirometry. Eur Respir J 2005, 26(2):319-338.

19. Waterer GW, Wan JY, Kritchevsky SB, Wunderink RG, Satterfield S, Bauer DC, Newman AB, Taaffe DR, Jensen RL, Crapo RO: Airflow limitation is underrecognized in well-functioning older people. J Am Geriatr Soc 2001, 49(8):1032-1038.

20. Mohamed Hoesein FA, Zanen P, Lammers JW: Lower limit of normal or FEV1/FVC $<0.70$ in diagnosing COPD: an evidence-based review. Respir Med 2011, 105(6):907-915.

21. Artigas MS, Loth DW, Wain LV, Gharib SA, Obeidat M, Tang W, Zhai G, Zhao $J \mathrm{H}$, Smith AV, Huffman JE, et al: Genome-wide association and large-scale follow up identifies 16 new loci influencing lung function. Nat Genet 2011, 43:1082-1090.

22. Cooper GM, Shendure J: Needles in stacks of needles: finding disease-causal variants in a wealth of genomic data. Nat Rev Genet 2011, 12(9):628-640.

23. Storey JD: A direct approach to false discovery rates. $J R$ Statist $\operatorname{Soc} B$ 2002, 64:479-498.

24. Dixon AL, Liang L, Moffatt MF, Chen W, Heath S, Wong KC, Taylor J, Burnett E, Gut I, Farrall M, et al: A genome-wide association study of global gene expression. Nat Genet 2007, 39(10):1202-1207.

25. Yang Y, Uhlig S: The role of sphingolipids in respiratory disease. Ther Adv Respir Dis 2011, 5(5):325-344.

26. Chi H: Sphingosine-1-phosphate and immune regulation: trafficking and beyond. Trends Pharmacol Sci 2011, 32(1):16-24.

27. Mechtcheriakova D, Wlachos A, Sobanov J, Kopp T, Reuschel R, Bornancin F, Cai R, Zemann B, Urtz N, Stingl G, et al: Sphingosine 1-phosphate phosphatase 2 is induced during inflammatory responses. Cell Signal 2007, 19(4):748-760.

28. Houle F, Poirier A, Dumaresq J, Huot J: DAP kinase mediates the phosphorylation of tropomyosin-1 downstream of the ERK pathway, which regulates the formation of stress fibers in response to oxidative stress. J Cell Sci 2007, 120(Pt 20):3666-3677.

29. Mukhopadhyay R, Ray PS, Arif A, Brady AK, Kinter M, Fox PL: DAPK-ZIPKL13a axis constitutes a negative-feedback module regulating inflammatory gene expression. Mol Cell 2008, 32(3):371-382.

30. Hao K, Niu T, Xu X, Fang Z: Single-nucleotide polymorphisms of the KCNS3 gene are significantly associated with airway hyperresponsiveness. Hum Genet 2005, 116(5):378-383.

31. Brutsche MH, Downs SH, Schindler C, Gerbase MW, Schwartz J, Frey M, Russi EW, Ackermann-Liebrich U, Leuenberger P: Bronchial hyperresponsiveness and the development of asthma and COPD in asymptomatic individuals: SAPALDIA cohort study. Thorax 2006, 61(8):671-677.

32. Miyamae T, Marinov AD, Sowders D, Wilson DC, Devlin J, Boudreau R, Robbins $P$, Hirsch R: Follistatin-like protein-1 is a novel proinflammatory molecule. J Immunol 2006, 177(7):4758-4762.

33. Schunemann HJ, Dorn J, Grant BJ, Winkelstein W Jr, Trevisan M: Pulmonary function is a long-term predictor of mortality in the general population: 29-year follow-up of the Buffalo Health Study. Chest 2000, 118(3):656-664.

34. Pike JW, Meyer MB, Bishop KA: Regulation of target gene expression by the vitamin D receptor - an update on mechanisms. Rev Endocr Metab Disord 2012, 13(1):45-55.

doi:10.1186/1471-2350-14-122

Cite this article as: Reardon et al:: Vitamin D-responsive SGPP2 variants associated with lung cell expression and lung function. BMC Medical Genetics 2013 14:122.

\section{Submit your next manuscript to BioMed Central and take full advantage of:}

- Convenient online submission

- Thorough peer review

- No space constraints or color figure charges

- Immediate publication on acceptance

- Inclusion in PubMed, CAS, Scopus and Google Scholar

- Research which is freely available for redistribution

Submit your manuscript at www.biomedcentral.com/submit 